\title{
Research on the User Acceptance Model of WeChat Public Platform Service
}

\author{
Bin Pan ${ }^{1, a}$, Hongxia Guo ${ }^{2, b^{*}}$ and Yuheng Du $u^{3, c}$ \\ ${ }^{1}$ College of Management Science, Chengdu University of Technology, Chengdu, China \\ ${ }^{2}$ College of Information Science and Engineering, Chengdu University, Chengdu, China \\ ${ }^{3}$ Qihoo 360 Technology Co. Ltd. , Beijing, China \\ apan_swpi2003@163.com, b32174366@qq.com, ${ }^{\mathrm{C}} 749338336 @ q q . c o m$
}

Keywords: WeChat public platform service; User acceptance model; Model verification; Structural equation modeling

\begin{abstract}
Based on the problem of the user acceptance of WeChat public platform service, the technology acceptance model theory is used to model the influence factors, and the relationship hypothesis between various factors is proposed. AMOS7.0 is used to evaluate and correct the model and construction according to the questionnaire survey data, and the direct effect value and indirect effect value of various influence factors on the use behavior are calculated by correlation coefficient.
\end{abstract}

\section{Introduction}

With the rapid development of Internet+, the research on the application of Internet products becomes a hot spot, and the research on the user acceptance for products is an important part of it. WeChat public platform is an important function module on WeChat platform, and through it, any individual or company can send text, pictures, image text, voice, video, and other content to fans of the WeChat public number. How to make the service acceptable to public is directly related to the promotion and development of the influence of WeChat public platform [1].

\section{Theoretical Model and Research Hypothesis}

The technology acceptance model (TAM) is a widely used research model which is used to study the impact factors of information technology on individual acceptance [2, 3]. On the basis of TAM, combined with the theory of perceived value and consumer innovation, the user acceptance model of the WeChat public platform is constructed as shown in Fig.1:



Figure 1. WeChat public platform user acceptance model

Among them, the perceived ease of use is defined as the ease of using the WeChat public platform and completing the target operation every time. Perceived usefulness is defined as the users' perception degree that the product can help them to solve problems and meet the needs of 
using WeChat public platform service. The definition of perceived value is the trade-off between the user's subjective perception of the benefits they gain and the cost of the effort in the process of using the WeChat public platform service. The income mainly includes the quality of service, price, service experience, credibility and use efficiency of the products. The cost mainly includes the consumed time, capital, physical strength and spirit when they use the products [4]. The definition of perceived risk is that in the process of obtaining and using the WeChat public platform service, the uncertainty of the internal and external environment and the incorrect decisions of users lead to adverse consequences, so users perceive risks in the process of obtaining and using services. The social impact is defined as users' perception for the influence of their own relatives and friends and the mainstream social groups on their own use for WeChat public platform services. Consumer innovation is defined as the desire of users to accept and use the new service model of the WeChat public platform service independently. The consumption experience is defined as the user's perception of the sense, emotion, thought, action, association and other multilevel experiences in the process of using the WeChat public platform service. Behavioral attitude is defined as the user's preference, the positive emotion or dislike and negative emotion in the process of using the WeChat public platform. The behavioral intention is defined as the intensity of users' willingness to use WeChat public platform services, which is manifested in the frequency and cumulative usage time of using this product everyday.

In the model, the arrows in the graph represent their correlation, and the relationship hypothesis in the model is as follows:

H1a: Perceived ease of use will have a positive impact on perceived usefulness.

H1b: Perceived ease of use will have a positive impact on behavioral attitude.

$\mathrm{H} 2$ : Perceived usefulness will have a positive impact on behavioral attitude.

H3: Perceived value will have a positive impact on behavioral attitude [5].

H4a: Perceived risk will have a positive impact on perceived value.

$\mathrm{H} 4 \mathrm{~b}$ : Perceived risk will have a positive impact on behavioral attitude.

$\mathrm{H} 4 \mathrm{c}$ : Perceived risk will have a negative impact on consumer innovation.

H5: In the process of users' use of WeChat public platform services, their own consumer innovation will have a positive impact on the usage intention.

H6a: Social impact will have a positive impact on behavioral attitude.

H6b: Social impact will have a positive impact on the usage intention.

H7: The usage experience will have a positive impact on the user's usage intention.

H8: The behavioral attitude of users using WeChat public platform services will have a positive impact on the usage intention.

\section{Questionnaire Design}

This study uses the questionnaire survey to obtain basic data. Around the 9 variables in the model, a total of 33 questions are set up in the questionnaire. Questions are based on the structure of Likert five-level scale. 
Table 1 Table of perceived usefulness measurement questions

\begin{tabular}{cl}
$\begin{array}{c}\text { Numbe } \\
\mathrm{r}\end{array}$ & \multicolumn{1}{c}{ Measurement questions } \\
\hline PV1 & $\begin{array}{l}\text { I think the WeChat public platform service conveys emotions, which can } \\
\text { make the relationship between me and service providers closer. }\end{array}$ \\
PV2 & $\begin{array}{l}\text { I think the WeChat public platform service can increase my cognition } \\
\text { understanding of society. }\end{array}$ \\
PV3 & $\begin{array}{l}\text { I think the project type and functional design of WeChat public platform } \\
\text { service can fully meet my needs. }\end{array}$ \\
PV4 & $\begin{array}{l}\text { A large number of promotions launched by businesses on the WeChat } \\
\text { public platform will make me more willing to use its services. }\end{array}$ \\
PV5 & $\begin{array}{l}\text { I think it is faster, more efficient and flexible to use the WeChat public } \\
\text { platform to obtain network services from businesses, enterprises and } \\
\text { governments. }\end{array}$ \\
\hline
\end{tabular}

Because of the limit of the length, here is only a list of perceived value measurement questions. Questions are designed from five dimensions [6]: functional value, social value, emotional value, economic value, and efficiency value, as shown in Table 1.

\section{Model Verification}

From this research model, we can see that there are multiple collinearity problems among variables, so the structural equation modeling method (SEM) is very suitable for data analysis verification.

There are four exogenous latent variables in the model, which are $\xi_{1}$ : perceived ease of use, $\xi_{2}$ : social impact, $\xi_{3}$ :usage experience, and $\xi_{4}$ : perceived risk. 4 exogenous latent variables correspond to 15 exogenous manifest variables, and each exogenous manifest variable corresponds to one question in the questionnaire.

There are five endogenous latent variables, which are $\eta_{1}$ : perceived usefulness, $\eta_{2}$ : perceived value, $\eta_{3}$ : consumer innovation, $\eta_{4}$ : behavioral attitude, and $\eta_{5}$ : usage intention. 5 endogenous latent variables correspond to 17 endogenous manifest variables, and each endogenous manifest variable corresponds to a question in the questionnaire.

The AMOS7.0 tool is used to establish a structural equation model for 264 selected questionnaires. The fitting of the model is analyzed, and the normalized regression coefficient and the significance of each path are calculated, so as to understand the correlation between the variables. The analysis results and the path relationship between the variables are shown in Fig. 2 . 


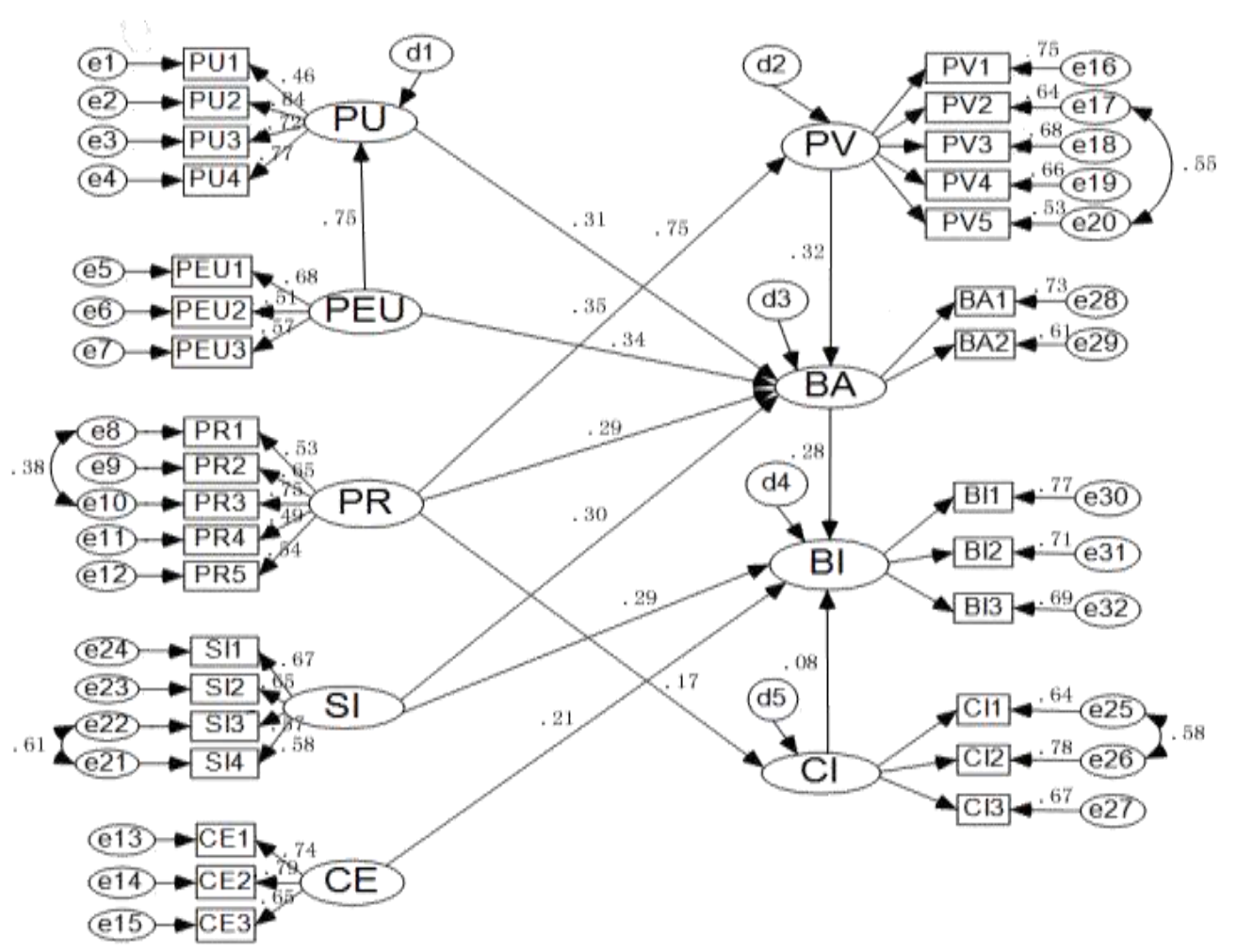

Figure 2. The result of path relation analysis among different variables

The ratio of chi-square and degree of freedom, GFI, and AGFI of the selected model indicate that the users of this study can accept the fitting of the WeChat public platform service acceptance model statistically. The model evaluation table is shown in Table 2:

Table 2 Model evaluation table

\begin{tabular}{lcc}
\hline \multicolumn{1}{c}{ Index } & $\begin{array}{c}\text { Value of the } \\
\text { model }\end{array}$ & Evaluation result \\
\hline $\begin{array}{l}\text { Ratio of chi-square and degree of freedom } \\
\left(\chi^{2} / \mathrm{df}\right)\end{array}$ & $\begin{array}{c}1179.2 / 571=2.07 \\
\text { Goodness of Fit Index(GFI) }\end{array}$ & $\begin{array}{c}\text { Good } \\
\text { Acceptable }\end{array}$ \\
Adjusted Goodness of Fit Index(AGFI) & 0.734 & $\begin{array}{c}\text { Acceptable } \\
\text { Model Comparative Fit Index(CFI) }\end{array}$ \\
Root Mean Square Error & 0.856 & $\begin{array}{c}\text { Acceptable } \\
\text { Good }\end{array}$ \\
Approximation(RMSEA) & 0.078 & \\
Non-normed fit index(NNFI) & 0.826 & Acceptable \\
\hline
\end{tabular}

Using AMOS software to view the result output can obtain the C.R value, and the P value among the variables, so as to determine the significance of the estimation of the variable relationship. We can see that only the impact of perceived risk on consumer innovation $(\mathrm{CI}<=\mathrm{PR})$ and the impact of consumer innovation on the usage intention $(\mathrm{BI}<=\mathrm{CI})$ are not significant. In the original model, we delete the relationship between the two variables of $\mathrm{CI}<=\mathrm{PR}$ and $\mathrm{BI}<=\mathrm{CI}$, and evaluate the modified result model again. After the test, the final model is shown in Fig.4. 


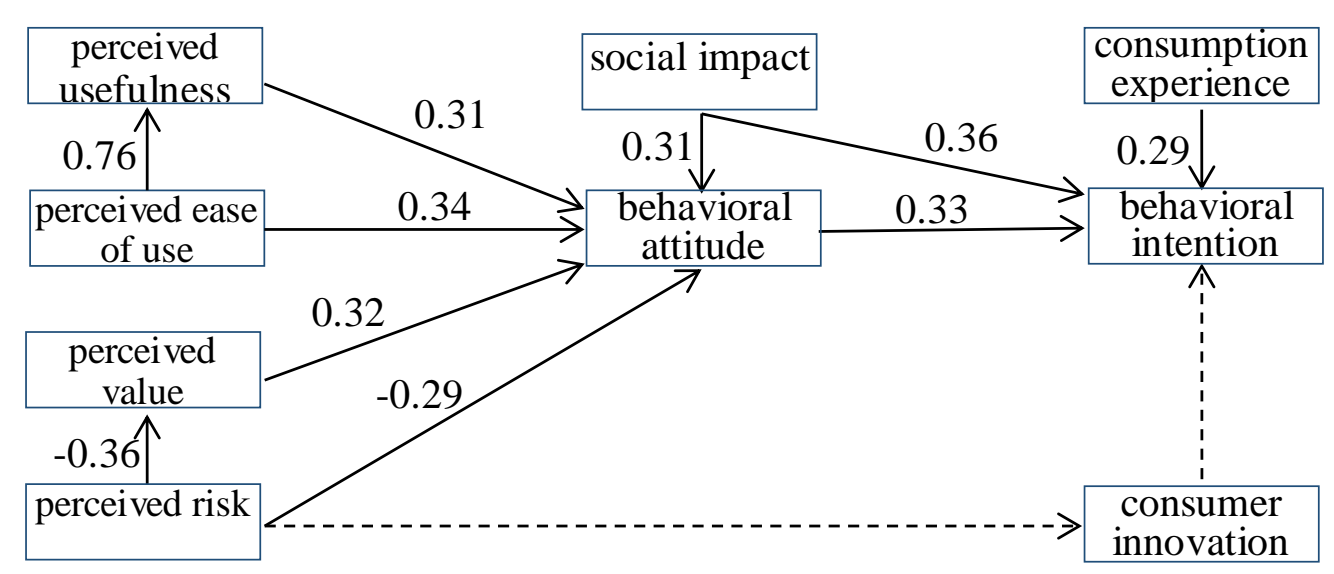

Figure 3. Relation diagram of each variable in the final model

From the above analysis, the direct effect and indirect effect of each variable on the use behavior can be calculated by the correlation coefficient between various variables, as shown in Table 3:

Table 3 The impact effect of each variable on the use behavior

\begin{tabular}{lccc}
\hline $\begin{array}{c}\text { Independent variables } \\
\text { and intermediate } \\
\text { variables }\end{array}$ & $\begin{array}{c}\text { Direct } \\
\text { effect }\end{array}$ & Indirect effect & Overall effect \\
\hline perceived usefulness & N/A & $0.31 \times 0.33$ & 0.102 \\
perceived ease of use & N/A & $0.76 \times 0.31 \times 0.33+0.34 \times 0.33$ & 0.189 \\
perceived value & N/A & $0.32 \times 0.33$ & 0.097 \\
perceived risk & N/A & $-0.36 \times 0.32 \times 0.33+(-0.29 \times 0$. & -0.995 \\
& 0.36 & $33)$ & 0.462 \\
social impact & 0.29 & N/A & 0.29 \\
consumption experience & 0.33 & N/A & 0.33 \\
behavioral attitude & . &
\end{tabular}

Note: N/A indicates that there is no relationship between variables.

According to the effect on the usage intention, the independent variables and all intermediate variables are sorted in ascending order. Perceived value $(0.097)<$ perceived risk $(-0.995)<$ perceived usefulness $(0.102)<$ perceived ease of use $(0.189)<$ consumption experience $(0.29)<$ behavioral attitude $(0.33)<$ social impact $(0.462)$.

\section{Conclusion}

In addition to the hypothesis of the relationship between consumer innovation and usage intention, and the hypothesis of the relationship between perceived risk and consumer innovation, the rest of the hypotheses are all established. The WeChat public platform can also be further promoted in many aspects, including the following points:

The perceived usefulness and perceived value of the model will directly or indirectly affect the user's usage intention. Tencent also needs to further expand the depth and breadth of the functions of WeChat public platform, meet the Internet use needs of users for basic necessities of life.

The perceived risk in the model have a adverse effect on the user's usage intention. Tencent must further strengthen the management of the public number operator, further improve the authentication system and process of the WeChat public number, set up platform running criteria, and increase the penalties for illegal account operators. 
The social impact will have a favorable impact on the user's usage intention. The WeChat public platform needs to further integrate all the resources of the whole society and build a closed loop ecosystem with government agencies, public institutions, enterprises, media and individuals.

\section{Acknowledgements}

The authors thank for the financial support of youth fund project of Sichuan province education office(No.10ZB088), youth key teachers training plan of Chengdu university of technology (No.10912-JXGG201413) and teaching reform project of Chengdu university(No.cdjgb2017111).

\section{References}

[1] F. Ji, X. H. Zhang: Information Studies:Theory \& Application, Vol. 38 (2015) No.12, p.77-81. (In Chinese)

[2] V. Venkatesh, M.G. Morris, G.B. Davis, F.D. Davis: MIS Quarterly, Vol. 27 (2003) No. 3, p.425-478.

[3] P. Bian: Research on Library Science, (2012) No.1, p.2-6. (In Chinese)

[4] P. Kotler, K. L. Keller: Marketing Management, 14th ed. (Prentice Hall, USA 2012), p.33-62.

[5] X.Y. Wang: The Empirical Study for Customer Acceptance Model of Online Banking based on TAM. (MS. Shandong University, China, 2012), p.36-37. (In Chinese)

[6] J. N. Sheth, B. J. Newman, B. L. Gross: Journal of Business Research, Vol. 22 (1991) No.2, p.159-170. 